\title{
The Politico-Economics of Electricity Planning in Developing Countries: A Case Study of Ghana
}

\author{
Yakubu Abdul-Salam ${ }^{\mathrm{a},{ }^{*},}$ Euan Phimister ${ }^{\mathrm{b}}$
}

a,* Corresponding author: Yakubu Abdul-Salam, The James Hutton Institute, Craigiebuckler, Aberdeen, AB15 8QH; yakubu.abdul-salam@hutton.ac.uk; Tel: +44(0)1224395453

${ }^{\mathrm{b}}$ Aberdeen Centre for Research in Energy Economics and Finance, University of Aberdeen, Aberdeen, UK; e.phimister@abdn.ac.uk: Tel: +44(0)1224273855

\begin{abstract}
Off-grid technologies are increasingly being proposed as a way of ensuring cost efficient universal access to electricity in many developing countries. However, many un-electrified communities would prefer access to electricity via the national grid rather than off-grid technologies. Electricity planning based on cost efficiency alone could therefore be undermined by political pressure from discontented communities that are assigned off-grid technologies. Using a case study of un-electrified communities in Ghana, we develop an electricity planning algorithm based on hierarchical lexicographic programming and consider specifications where the priorities are adjusted to give weight to 1) cost efficiency and 2) political economy considerations so that communities with larger populations (and therefore votes) are given priority in terms of grid electrification. The results emphasise the need to incorporate the political economy considerations in the national planning of universal electrification, showing significant regional differences in terms of where grid extensions ought to be placed. Incorporating a political economy perspective in national planning also suggests that the most important policy trade-offs shift from considering the grid versus offgrid balance to focussing more on the effectiveness of grid investment in providing universal access.
\end{abstract}

Keywords: Electricity Planning; Grid; Off-grid; Algorithms; Political Economy; Ghana. 


\section{Highlights}

- There is a focus on grid and off-grid electricity planning based on economics

- However community preferences for grid introduces a political dimension to planning

- We develop an algorithm to examine the politico-economics of electricity planning

- We find different priorities yield significant regional differences in grid access

- We find that greater policy focus on the effectiveness of grid investment is needed 


\section{Introduction}

It is estimated that up to 1.3 billion of the world's population have no access to electricity and of these some 97\% reside in the world's developing regions (IEA WEO, 2014). The situation is most pronounced in sub-Saharan Africa (SSA) where the overall electrification rate is about $33 \%$ only (IEA WEO, 2014) with the rural rate lower still. The positive correlation between access to electricity and development is long established (Goldemberg, 2000), and although access to electricity in itself is not a remedy for development (Bhattacharyya, 2006), modest access to electricity (e.g. for lighting) can have substantial benefits on the welfare of the poor (World Bank, 2008).

In many cases, un-electrified rural settlements are remote from existing grid networks and thinly populated. High fixed costs mean the per capita cost of extending access to electricity via grid networks to these settlements can be very high and uneconomical. Meanwhile the high potential for the use of off-grid systems in SSA, particularly drawing on renewable resources such as wind and solar has been recognised by a range of authors including Buys et al. (2007) and Painuly and Fenhann (2002). In this context, a number of electricity planning algorithms that are capable of determining grid or off-grid compatibility of un-electrified settlements have been proposed. For grid assigned settlements, they also determine optimal routing into the existing grid network. They include the algorithms by Lambert and Hittle (2000), Amador and Dominguez (2005), Parshall et al. (2009), Deichmann et al. (2011), and Levin and Thomas (2012).

However these algorithms prioritize cost efficiency and implicitly assume that off-grid and grid electrification are of equal value and that financing is equally available. There is ample evidence to show that un-electrified communities in low income countries prefer to be 
connected via the grid. Survey evidence from Ghana suggest that communities are willing to "wait for the national grid no matter how long it takes" (Bawakyillenuo, 2012, p.417, para 1). Palit and Chaurey (2011) also report that many communities perceive off-grid technologies as inferior due to its fixed availability and limited supply, while Bhattacharyya (2013) highlights that access to off-grid technologies is often simply seen as a transition to grid technology. Such community preferences for the grid may be well founded if communities believe that grid electrification is more able to allow for future electricity demand growth, so that access through the grid provides a community with an inbuilt future economic advantage over electrification via off-grid technologies.

In reality these community preferences for grid electrification can feed into how the political process determines investments in grid and off-grid electrification. ${ }^{1}$ Bawakyillenuo (2007) highlights the significant role that politicians' promises of grid access play within political campaigns in Ghana whilst Brown and Mobarak (2009) and Min (2011) find evidence that democracy appears to improve the electricity access of communities who are less prosperous (hence less cost efficient to grid connect) but have higher electoral weight (i.e. votes). There is therefore the need to reflect these preferences and influences in designing methods for electricity planning in developing countries. Electricity planning solely based on the economics of grid and off-grid technologies may be undermined by the political process as discontent off-grid assigned communities with political clout (votes) exercise political pressure for grid electrification.

\footnotetext{
${ }^{1}$ Although electricity is a private good, the goal of universal electricity access in development and the existence of natural monopolies in transmission and distribution mean that governments are deeply involved in the development and regulation of the electricity sector (Scott and Seth, 2013). Generally political power does affect the allocation of public goods across individuals and groups (Banerjee and Somanathan, 2007).
} 
This paper introduces a hierarchical lexicographic programming algorithm to solving the problem of planning for universal electricity access in developing countries. The algorithm determines the grid and off-grid compatibility of settlements and simultaneously routes grid assigned settlements into the existing grid network. Additionally, it allows flexibility in specifying priorities reflective of both cost efficiency and political economy considerations. We apply the algorithm to a detailed spatial country level data from Ghana. Specifically, cost efficient planning solutions are derived when electricity demand is prioritised for grid electrification, while political economy of electrification is captured by alternatively prioritising population. These different priorities can lead to quite different outcomes. As demand for electricity and economic development are positively correlated, prioritising demand leads to cost efficient solutions because communities and regions which are already most economically developed are chosen for grid extension. In contrast, prioritising population in grid extension will give more weight to communities with larger populations (reflecting their electoral weight), independent of their economic development status.

The plan of the remainder of the paper is as follows. In the next section we introduce the hierarchical lexicographic programming algorithm developed in this paper and discuss two of the existing cost effective algorithms. These are the algorithms proposed by Parshall et al. (2009) and Deichmann et al. (2011). We apply these three algorithms to Ghanaian data on un-electrified settlements in order to validate the new hierarchical lexicographic programming approach and to show how the cost and political economy implications of the different approaches compare. ${ }^{2}$ In section 3 we discuss the data and assumptions required to

\footnotetext{
2 The three algorithms applied in the paper were coded and implemented using the General Algebraic Modelling Systems (GAMS) software. A copy of the GAMs code developed for all three algorithms is available from the corresponding author.
} 
apply the three approaches to the spatial Ghana data. Section 4 discusses our results. We present two sets of results using the hierarchical lexicographic programming algorithm. The first prioritises the demand of unconnected consumers and which promotes cost efficiency. The second prioritises the connection of all unconnected individuals equally hence capturing the political economy of grid access where voting can influence policy decisions. We conclude in Section 5 with a discussion of the policy implications of our findings.

\section{Methods}

Planning how best to provide access to electricity to those currently without access is a complex spatial problem. To simplify the problem, we follow previous authors and focus on un-electrified settlements to determine the appropriate pattern of where to extend the grid and where to use off-grid technologies whilst allowing for the relative costs of each. The complexity of the underlying optimization problem means a global cost minimum can typically not be obtained for realistic cases and therefore heuristic methods are required. ${ }^{3}$

Before discussing the new algorithm introduced in this paper, we first discuss two existing algorithms in the literature that we also apply to the Ghanaian data to validate our new approach. These are the algorithms developed by Parshall et al. (2009), herein referred to as the PA method; and by Deichmann et al. (2011), herein referred to as the DA method. ${ }^{4}$

In practice, planning to provide access to electricity is a dynamic process, i.e. grid extension or new off grid investment takes place sequentially, with re-planning and changes to the original investment plan possible after initial investments have been made. Here, following

\footnotetext{
${ }^{3}$ The global cost minimum can only be reliably found in small scale problems (Abdul-Salam, 2015).

${ }^{4}$ An IDE version of the PA algorithm is accessible at http://networkplanner.modilabs.org/docs/.
} 
previous studies we abstract from this and assume a single plan is implemented in a single year and so the modelling has no temporal dimension and answers the question of the cost of immediate universal electrification.

\subsection{The PA Method}

This approach begins by computing the internal grid cost for un-electrified settlements. For each settlement, this cost is computed as the sum of the cost of connecting its households and institutions including the cost of MV-LV transformers, LV lines, internal household wiring costs, etc. Also for each un-electrified settlement, the costs of the off-grid technologies under consideration are calculated. If the internal grid cost for an un-electrified settlement is less than the cost of all off-grid technologies being considered, that settlement is identified to be 'eligible' for grid connection. For each eligible settlement a value $M V_{\max }$ is calculated as the maximum allowable length of a new primary MV line to be extended from the existing MV distribution network to the settlement such that the total grid cost (i.e. internal grid cost plus cost of incoming primary MV line) is less than or equal to the cost of the least cost off-grid technology for the settlement in question. At each iteration, one eligible un-electrified settlement is connected to the national grid. The connected settlement is served with an MV extension that is less than or equal to its $M V_{\max }$ value. These connections are based on the minimum spanning tree (MST) algorithm (Kruskal, 1956). Given a set of nodes, the MST algorithm finds the network of lines that connects all the nodes such that the total length of lines is the minimum possible, and that no loops are present. The PA algorithm terminates when all or at least one of the following conditions are reached; (1) all eligible un-electrified settlements have been connected to the network; or (2) the remaining eligible un-electrified settlements are located further from the national grid than their $M V_{\max }$ value in which case 
they are assigned their cheapest off-grid technology. The PA method has been adapted for use in a number of studies including Sanoh et al. (2012) and Kemausuor et al. (2014).

\subsection{The DA Method}

This approach identifies the $n$ un-electrified settlements and $k$ power generation and/or bulk supply points (BSPs) in a subject country. It is assumed that $n \geq m$. The algorithm sets out by finding the un-electrified settlement with the highest aggregate demand within a specified threshold radius $(120 \mathrm{~km})$ of the existing grid network. The maximal demand settlement found is then assigned a BSP and connected to the nearest generation or BSP settlement in the existing national grid network using a high voltage (HV) line. All the un-electrified demand settlements within the threshold radius of the newly assigned BSP settlement are then connected to the new BSP using medium voltage (MV) distribution lines. These connections are done via the MST algorithm. The levelised cost for grid (including MV and HV capital and recurrent costs) as well as the off-grid technologies under consideration are calculated for the geographic zone. The geographic zone is then served its least levelized cost technology. This procedure is repeated until all of the un-electrified settlements are within a geographic zone.

\subsection{Hierarchical Lexicographic Programming Method (HLM)}

We develop this heuristic based on a hierarchical lexicographic programming (Kalvelagen, 2002), with grid compatibility of groups of settlements rather than individual settlements considered in each iteration. The multiple decision making basis of this approach draws from methods used to solve the electrical districting problem (Bergey et al, 2003). Define $n$ as the set of un-electrified settlements and assume that $m \leq n$ settlements are to be electrified via 
grid extension. The main step of the method is to determine which $m$ settlements should be connected to the grid, with the remaining $(n-m)$ settlements served by off-grid technologies. These $m$ un-electrified settlements are selected to be connected to the grid network using a set of 3 priorities within a hierarchical lexicographic programme. This problem is then solved for various values of $m$ from $m=0$ (no settlements are grid connected) to $m=n$ (all $n$ settlements are grid connected), to understand how total costs vary as the balance between grid and off-grid varies.

We consider two specifications within this approach. In the first, to prioritise cost efficiency, we draw on the evidence on determinants of grid electrification costs to determine the three priorities as 1) maximize aggregate demand in the selected set of $m$ settlements, 2) minimise collective distance (maximising affinity) of the settlements from the existing grid and 3) minimize inter-settlement dispersion (i.e. maximising clustering) of settlements (World Bank, 2008; Nguyen, 2007). Higher aggregate demand reduces levelised cost of grid electrification, while distance of an un-electrified settlement to the existing grid is also an important cost factor and has been used by policy makers to determine community connection in World Bank projects (World Bank, 2008). Finally, maximizing the degree of clustering reduces costs by minimising the length of inter-settlement MV distribution lines needed to connect a group of settlements to the grid.

The multiple objectives are incorporated using hierarchal lexicographic optimization (Kalvelagen, 2002), where higher priorities are imposed as constraints on subsequent priorities but allowing for some relaxation. The full specification of the hierarchal 
lexicographic optimization for the first specification that prioritises cost efficiency is as follows $;{ }^{5}$

\section{Priority 1}

$\max _{x}$ demand $=\sum_{i} \operatorname{dem}(i) * x(i)$

S.t

$\sum_{i} x(i)=m$

$x \in\{0,1\}$

\section{Priority 2}

$\min _{y}$ sumDist $_{\text {grid }}=\sum_{i} \operatorname{dist}_{\text {grid }}(i) * y(i)$

s.t

$\sum_{i} y(i)=m$

$\sum_{i} \operatorname{dem}(i) * y(i) \geq(1-\varepsilon \%) *$ demand

$y \in\{0,1\}$

\section{Priority 3}

$$
\begin{aligned}
& \min _{z} \text { dispersion }=\sum_{i, j} \operatorname{dist}(i, j) * z(i) * z(j) \\
& \text { s.t } \\
& \sum_{i} z(i)=m \\
& \sum_{i} \operatorname{dem}(i) * z(i) \geq(1-\varepsilon \%) * \text { demand }^{*} \\
& \sum_{i} \text { dist }_{\text {grid }}(i) * z(i) \leq(1+\varepsilon \%) * \text { sumDist }_{\text {grid }} \\
& z \in\{0,1\}
\end{aligned}
$$

\footnotetext{
5 In the second specification population is prioritised to reflect political economy considerations. In this specification, demand of a settlement does not determine its eligibility for grid connection.
} 
where $\operatorname{dem}(i), \operatorname{dist}_{\text {grid }}(i)$ and $\operatorname{dist}(i, j)$ is electricity demand in settlement $i$, its minimum distance to the existing grid and the distance between settlement $i$ and $j ; x(i), y(i)$ and $z(i)$ are binary variables indicating whether settlement $i$ is selected in the set of $m$ settlements. Finally demand, sumDist ${ }_{\text {grid }}$ and dispersion represent aggregate demand, sum of distances to the existing grid and the degree of dispersion in the $m$ selected settlements respectively; $\varepsilon \%$ represents the level of relaxation or tolerance.

Once the $m$ group of settlements to be connected to the grid are determined, the MST algorithm determines the MV distribution network. Each of the remaining $n-m$ settlements is simply allocated its least cost off-grid alternative. The total electrification cost given $m$ is the sum of the cost of grid electrification for the $m$ grid assigned settlements and the cost of off-grid supply for the $n-m$ remaining settlements.

\section{Data}

To provide an illustration of the impact and implications of taking political economy preferences into account within the planning process. We apply the methods described above to case study data for Ghana. ${ }^{6}$ Although overall rates of electrification in Ghana are higher relative to other countries in the region, rural electrification remains low at around $30 \%$ in 2010 (Kemausuor, 2011). To allow for off-grid solar and wind power options we use geospatial data for over 5000 settlements in Ghana from the Solar and Wind Resource Assessment project (SWERA, 2011). For each settlement the geographic coordinates as well

\footnotetext{
${ }^{6}$ The case study is intended as illustrative with the data and assumptions sufficiently realistic so as to provide better insights into how taking political economy preferences into account might change outcomes and tradeoffs. The approach follows that of Deichmann et al. (2011) who illustrated their algorithm using GIS data and GIS procedures similar to ours. One area where in fact we include more realism is that while they ignored the existing grid network we do allow for this.
} 
as the solar and wind resource potential are given. For settlement population estimates, we use Afripop (2012) data which provides population distributions in Ghana. Both datasets are incorporated into standard GIS software. ${ }^{7}$

In the SWERA datasets, all settlements are presented as points. We however require the geographic area $\left(\mathrm{km}^{2}\right)$ of each settlement in order to compute a number of quantities e.g. the number of transformers needed for grid electrification. Consistent with Deichmann et al. (2011), we approximate the geographic areas of the settlements using a Thiessen polygon transformation of the points with the geometric area of a polygon defining the geographic area of the settlement point it represents. We also required the geographic boundaries of each settlement to compute its population using the Afripop (2012) dataset. The Afripop dataset is provided as a GIS raster. By superimposing the raster over the Thiessen polygons created, we calculate the total population of each settlement by summing up the number of people in the raster grid covered by the Thiessen polygons. The total population extracted for all settlements using this method is 24.32 million which is consistent with the officially reported Ghana population for 2010 (Ghana Statistical Service, 2012).

\subsection{Electrification Status of a Settlement}

SWERA does not indicate the electrification status of the settlements. However, under the Self-Help Electrification Project of the National Electrification Scheme of Ghana, settlements within $20 \mathrm{~km}$ of the existing grid are eligible for grid electrification (Bawakyillenuo, 2009). We therefore apply an outward buffer of $20 \mathrm{~km}$ around the Ghana HV and MV network with all settlements within or at the boundary of this buffer assumed to be electrified and

\footnotetext{
${ }^{7}$ All GIS operations are conducted in ARCGIS software (2013).
} 
settlements outside it assumed as un-electrified. Evidence suggests that some settlements close to the network are not in fact connected to the grid whilst others further than $20 \mathrm{~km}$ from the network are connected (GRIDCO, 2011) so this approximation will underestimate access to the grid. This procedure resulted 1086 settlements as un-electrified with the total population in these settlements being 3.24 million. This implied un-electrified population is $13 \%$ which is lower than the official reported figure of about $30 \%$. Finally in terms of the spatial data, the SWERA dataset does not indicate the existing generation and/or BSP locations on the transmission network. Using data provided by GRIDCO (2011) and ADB (2011), we have identified and digitised the approximate placement of 109 existing BSP and existing/potential grid generation locations. These locations form the starting nodes for extending the existing grid to un-electrified settlements.

\subsection{Electricity Demand}

Associated with each settlement we assume there will be a given level of electricity demand associated with domestic and productive activities. Following Parshall et al. (2009), we define domestic and productive demand on per household per year basis and allow for differences in the ability/willingness to pay for electricity across settlements by assuming that electricity demand for un-electrified households varies regionally (North/South) and by settlement depending upon population density (above/below 256 people $/ \mathrm{km}^{2}$ ). This yields four levels of demand for electricity per household as shown in Table 1. 


\begin{tabular}{|l|l|l|l|l|}
\hline $\begin{array}{l}\text { Demand } \\
\text { category }\end{array}$ & $\begin{array}{l}\text { Population } \\
\text { density } \\
(\text { people/km²) }\end{array}$ & $\begin{array}{l}\text { North/South } \\
\text { (i.e. proxy for } \\
\text { poverty rate) }\end{array}$ & $\begin{array}{l}\text { Household demand } \\
(\mathrm{kWh} / \mathrm{hh} / \text { year })\end{array}$ & $\begin{array}{l}\text { Productive demand } \\
(\mathrm{kWh} / \mathrm{hh} / \text { year })\end{array}$ \\
\hline $\begin{array}{l}\text { Sparse, } \\
\text { poor }\end{array}$ & $<256$ & North & 360 & 50 \\
\hline $\begin{array}{l}\text { Sparse, } \\
\text { non-poor }\end{array}$ & $<256$ & South & 600 & 100 \\
\hline $\begin{array}{l}\text { Dense, } \\
\text { poor }\end{array}$ & $>256$ & North & 360 & 75 \\
\hline $\begin{array}{l}\text { Dense, } \\
\text { non-poor }\end{array}$ & $>256$ & South & 1800 & 340 \\
\hline
\end{tabular}

Table 1: Electricity demand: Household electricity demand as a function of population density and geographic location (income) of settlements in Ghana.

Source: Adapted from Parshall et al. (2009)

Specifically we assume that incomes and economic activity in the Northern part of the country is lowest, with low density settlements there having the lowest domestic and productive electricity demand, while households in the South in high density settlements are assumed to have the highest incomes and hence have the highest domestic and productive electricity.

Domestic demand covers energy used in powering domestic gadgets such as light bulbs, radios, TV sets, etc. Productive demand covers energy use related to productive infrastructure. These may include mills, agro-processing equipment, schools and clinics, etc. Figure 1 describes the population and geographic area distributions of the demand levels. 


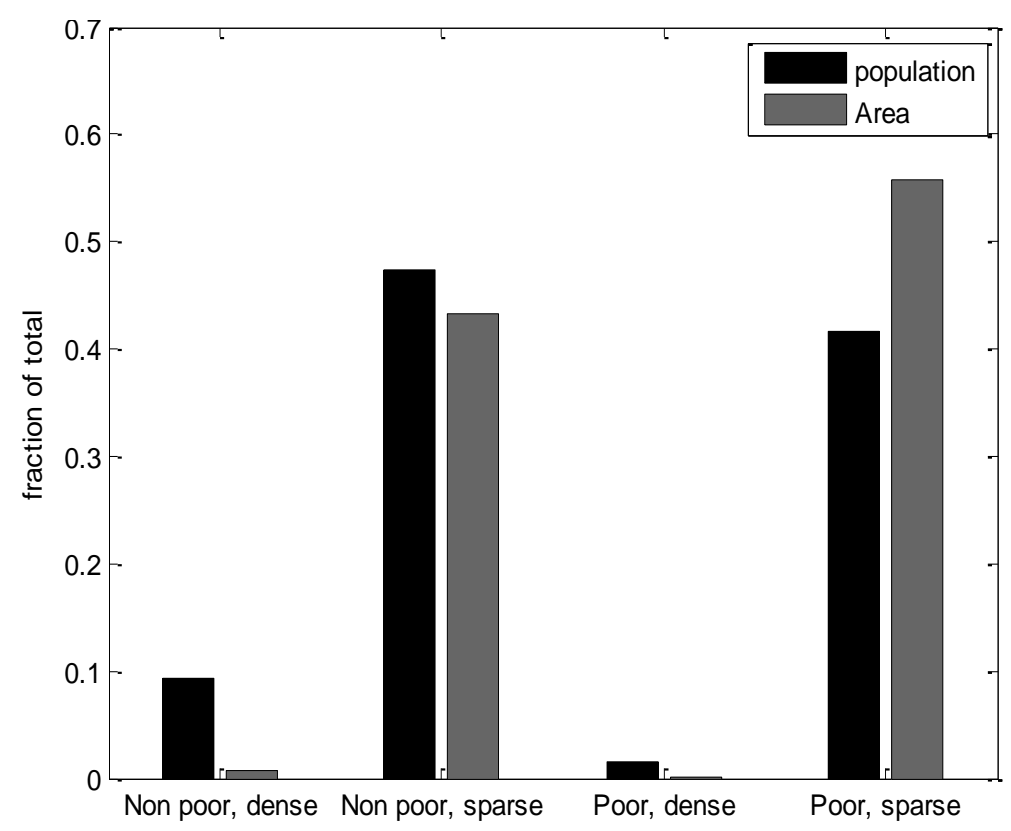

Figure 1: Electricity demand distribution: Population and area distributions of electricity demand categories.

Only $9.4 \%$ of the un-electrified population is categorised as the non-poor living in dense settlements. This population is found in the South-West region of the country and covers only $0.7 \%$ of the total un-electrified land area. $88 \%$ of the population is categorised as living in sparse settlements covering $99 \%$ of the total un-electrified land area whilst $43.2 \%$ of the population is categorised as poor.

\subsection{Cost Assumptions}

We require cost estimates on the components of the competing technologies as well as assumptions about their configuration. For parity in comparisons, each technology must provide access to electricity which satisfies the electricity demand of each un-electrified settlement.

Consistent with the available population data, 2010 is our base year. We use a combination of component costs and assumptions on technology configurations used previously by Parshall et al. (2009) and Deichmann et al. (2011), supplemented by updated information where 
appropriate. For components with low learning rates, e.g. MV line costs for grid, the assumptions for their costs are taken directly from Parshall et al. (2009). To reflect the significant changes in solar and wind technology costs, we update their estimates using values from NREL (2010). ${ }^{8}$ The full set of cost assumptions is reported in Appendix A (see Appendix A). Both grid expansion and minigrid involve LV lines to connect households and so total costs will depend on the locations of households within a settlement. Spatial information at this level of detail is however not available so we calculate the total length of household-household LV wiring required within a settlement by adapting the approach used in Zvoleff et al. (2009). Specifically by assuming that households are situated in a hexagonal configuration within $50 \%$ of the total land mass of each settlement, we can calculate average nearest neighbour of each household and hence the total length of household-household LV wiring required within a settlement (Abdul-Salam, 2015; Clark and Evans, 1954).

Finally for grid expansion we need to determine the number of MV-LV transformers required. Following Parshall et al. (2009), we assume that 50\% of a settlement's spatial area would need to be within range of a transformer. This reflects the tendency of households to cluster within a sub-region of a settlement rather than to spread evenly across it. We also assume that a transformer could cover a radius of $300 \mathrm{~m}$ as in Parshall et al. (2009). ${ }^{9}$ As the

\footnotetext{
${ }^{8}$ NREL provides cost data for 2010 in 2007 U.S. dollars. We use the U.S. CPI index to calculate the cost figures in 2010 U.S. dollars.

${ }^{9}$ Although we apply a $300 \mathrm{~m}$ threshold for both urban and rural settings for our base analysis, a $300 \mathrm{~m}$ threshold for a rural setting may be restrictive in some situations. The Ghana Statistical Service (2010) defines a rural location as one with less than 5000 persons and an urban location as one with more than 5000. We use this definition to identify rural and urban locations in our data and test the sensitivity of the $300 \mathrm{~m}$ threshold in these locations. We find that increasing the rural threshold to $400 \mathrm{~m}$ and $500 \mathrm{~m}$ will on average reduce the total cost of electrification by about $1 \%$ and $1.4 \%$ respectively across algorithms.
} 
area of the settlements is known, this allows a straightforward calculation to determine the number of transformers required for a settlement. ${ }^{10}$

The costs of providing electricity demand by standalone solar or wind are assumed to be independent of the configuration of households in a settlement. Following Parshall et al. (2009), we assume that standalone solar and wind installations satisfy each household's domestic demand, whilst a single diesel generator is available to satisfy a settlement's productive demand. However the total cost of solar technology or wind for a settlement requires the total number of panels or turbines required which will depend on total settlement demand and the solar and wind resources available. To determine the latter we follow the assumptions used by Deichmann et al. (2011). To convert solar resource we use their estimated linear regression model of the relationship between solar irradiation and solar energy output with the irradiation data from SWERA to provide potential solar energy output for each settlement. The number of panels required for each settlement is determined by its total domestic demand and solar energy output. Similarly, we use their model with the wind speed data to determine the electricity output from a $1 \mathrm{~kW}$ wind turbine for each settlement from which we can calculate the number of turbines required.

\subsection{Additional assumptions}

We assume a discount rate of $10 \%$ (the standard World Bank recommended rate for infrastructural projects in developing countries). For simplicity, we also assume a population, economic and electricity demand growth rate of $0 \%$. We assume the planning horizon for all

\footnotetext{
${ }^{10}$ A number of other possible grid costs are excluded from the current analysis. These include the costs of transmission reinforcements or scale up in electricity generation sources needed to support new grid demand, and the costs of inter-settlement MST MV distribution networks arising from geographic barriers, etc.
} 
technologies to be the lifetime of the component with the highest longevity (Pokharel, 2002). The lifetime of the grid network lines is the longest i.e. 40 years (Nguyen, 2007) hence we assume a planning horizon of 40 years. All technologies and their components with lifetimes less than 40 years are repeatedly replaced within this period. Given the above assumptions and cost estimates, we can calculate net present value of costs for electrifying each settlement with the respective off-grid technologies i.e. mini-grid, solar and wind. The various solution methods compare this information with the net present costs of grid expansion to determine the optimal balance of technologies.

The lifetimes of the technology components are 3 years (e.g. batteries), 5 years (e.g. minigrid generator), 10 years (e.g. transformers) and 20 years (e.g. solar panels). For components with 5, 10 and 20 year lifetimes, there are no residual values as final investments are made in the $35^{\text {th }}, 30^{\text {th }}$ and $20^{\text {th }}$ years respectively. For components with 3 year lifetimes however (i.e. batteries), the final investment is made in the $39^{\text {th }}$ year which implies a residual value of 1 year at the end of the planning horizon. However, batteries are relatively low cost items and given that the present cost of their purchase is discounted over 39 years, the monetary value would be low (i.e. $<1 \%$ of total cost across the different algorithms). We do not therefore factor their residual value in our analyses.

\section{Results and Discussion \\ 4.1 Prioritising Demand}

Figure 2 illustrates the solution of the hierarchical lexicographic programming method (HLM) where maximizing demand is the first priority which should lead to a cost efficient 
solution. ${ }^{11}$ It shows the total cost of universal access for un-electrified settlements for various combinations of grid and off-grid connections. Total cost is high when all settlements are connected using off-grid technologies. As the number of grid connected settlements increases total cost initially falls but as more settlements are connected the total cost increases sharply mainly because of the sharp increase in grid costs. This is because the additional settlements connected to the grid have lower demand, are of a greater distance from the grid and have lower clustering (i.e. higher dispersion). The minimum total cost of universal electrification arises when 781 out of the 1086 un-electrified settlements are grid connected with the remainder served by their cheapest off-grid technologies at a total cost of $\$ 4.19$ billion over 40 years. ${ }^{12}$

\footnotetext{
${ }^{11}$ As there are 6 possible priority orderings, experimentation was undertaken to explore the impact of changing the ordering of the priority levels. The cost estimates reported for HLM can also be obtained for 3 other priority orderings and are the lowest cost estimates obtainable using the HLM method.

${ }^{12}$ The tolerance level used here was 35\% which simulations showed yielded the best result for the prioritisation order specified in equations (1)-(3).
} 


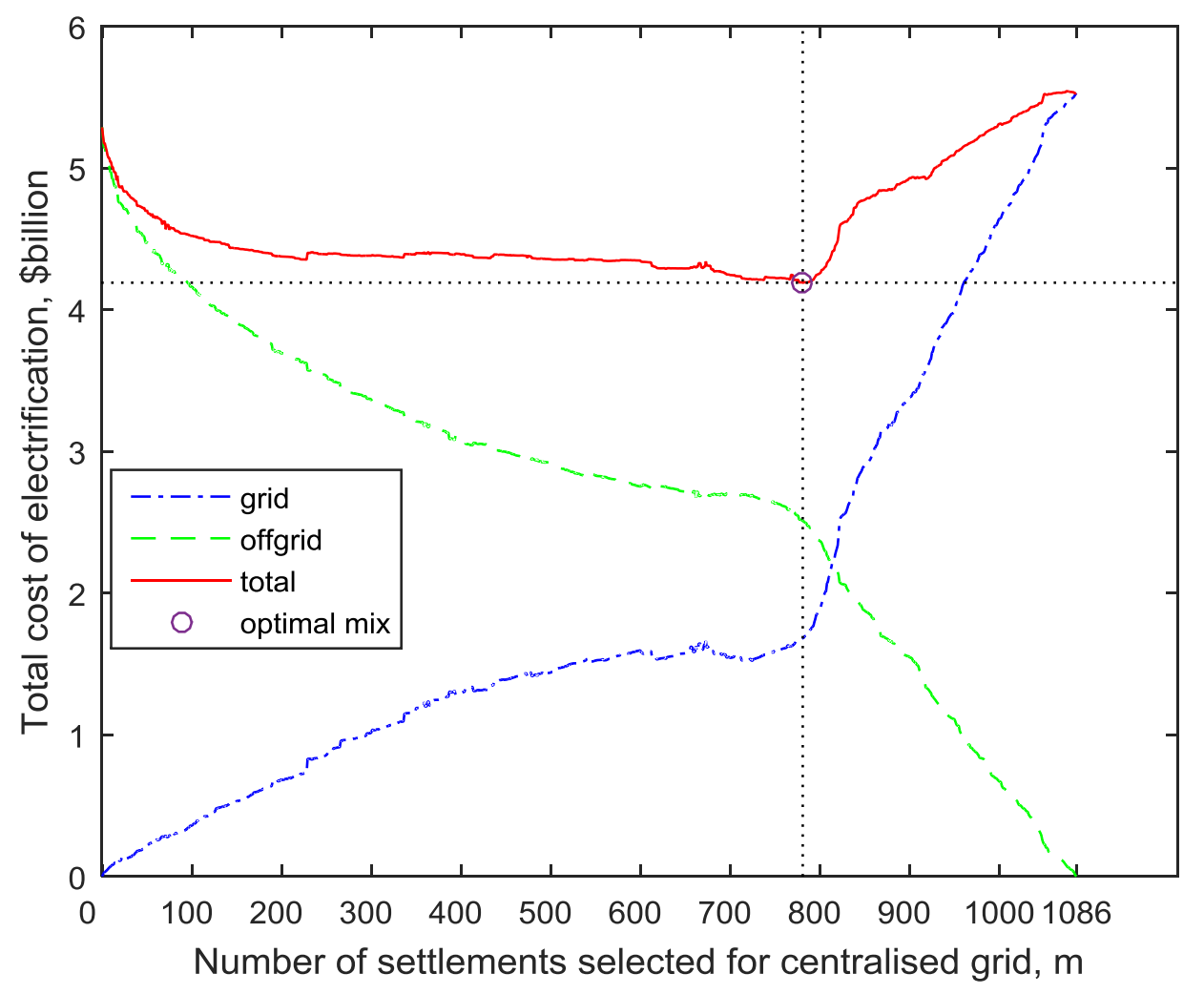

Figure 2: HLM solution prioritising demand: Total cost and cost structure by number of grid connected settlements.

To provide a comparison of how prioritising demand within the HLM approach performs in terms of cost efficiency, Table 2 reports the structure of its minimum cost solution against the minimum cost solutions found using PA and DA methods ${ }^{13}$ which were also coded and applied to the Ghana data in the present study.

\footnotetext{
${ }^{13}$ Comparisons of our PA and DA results to those of Kemausuor et al. (2014) and Deichmann et al. (2011) who also implement the respective algorithms for the case of Ghana is relatively difficult because of the different data and assumptions used. For example, as noted Deichmann et al. (2011) assume no existing transmission and distribution network. The work of Kemausuor et al. (2014) is more comparable and their estimate of the total cost of electrification in Ghana of \$US 696 million is significantly less than our estimate for the PA algorithm (\$US 4.008 billion). Most likely these differences are driven by differences in assumptions about household demand and the time horizon chosen which is 10 years in their study compared to 40 years here.
} 


\begin{tabular}{|c|c|c|c|c|}
\hline & & \multicolumn{3}{|c|}{ Algorithm } \\
\hline & & HLM & PA & DA \\
\hline \multicolumn{5}{|l|}{ Grid } \\
\hline & Cost, US \$ billion & 1.681 & 1.645 & 1.674 \\
\hline & LCOE, US\$/kWh & 0.139 & 0.128 & 0.138 \\
\hline & Cost per HH, US \$ & 5,440 & 4,461 & 5,333 \\
\hline & No. of settlements & 781 & 647 & 780 \\
\hline & Population covered, $\%$ & 0.477 & 0.568 & 0.484 \\
\hline \multicolumn{5}{|l|}{ Solar } \\
\hline & Cost, US \$ billion & 0.017 & 0.017 & - \\
\hline & LCOE, US\$/kWh & 1.200 & 1.200 & - \\
\hline & Cost per HH, US \$ & 19,683 & 19,683 & - \\
\hline & No. of settlements & 11 & 11 & - \\
\hline & Population covered, $\%$ & 0.001 & 0.001 & - \\
\hline \multicolumn{5}{|c|}{ Minigrid } \\
\hline & Cost, US $\$$ billion & 2.469 & 2.323 & 2.520 \\
\hline & LCOE, US\$/kWh & 0.393 & 0.420 & 0.399 \\
\hline & Cost per HH, US \$ & 7,347 & 8,405 & 8,113 \\
\hline & No. of settlements & 288 & 422 & 306 \\
\hline & Population covered, $\%$ & 0.518 & 0.426 & 0.516 \\
\hline \multicolumn{5}{|l|}{ Wind } \\
\hline & Cost, US \$ billion & 0.023 & 0.023 & - \\
\hline & LCOE, US\$/kWh & 0.505 & 0.505 & - \\
\hline & Cost per HH, US \$ & 8,695 & 8,695 & - \\
\hline & No. of settlements & 6 & 6 & - \\
\hline & Population covered, $\%$ & 0.004 & 0.004 & - \\
\hline & Total Cost, US $\$$ billion & 4.190 & 4.008 & 4.194 \\
\hline & Average LCOE, $\$ / \mathrm{kWh}$ & 0.270 & 0.255 & 0.273 \\
\hline & Average Cost per $\mathrm{HH}, \$$ & 6,460 & 6,179 & 6,735 \\
\hline
\end{tabular}

* All costs are NPV values assuming 10\% discount factor over 40 years planning horizon. All technologies and components with lifetimes less than 40 years are repeatedly replaced within this period.

Table 2: Minimum univeral electrification costs: HLM versus other methods

The PA method yields the lowest total cost solution with the net present value of electrification costing $\$ 4.008$ billion over 40 years. This is about $4.4 \%$ lower than the DA and HLM solutions. The average NPV cost of providing electricity access per household ranges from about $\$ 6200$ per household for the PA method to just under $\$ 6700$ per household for the DA and HLM cases. In terms of balance between grid extension versus off-grid supply, the 
PA solution has the largest proportion of un-electrified population covered via grid at $56.8 \%$, with mini-grids being suggested for $42.6 \%$ of the population, and the remaining population covered by standalone solar or wind technologies. Although the DA and HLM solutions suggest a somewhat lower proportion of the population covered by grid $(48.4 \%$ and $47.7 \%$ respectively), there are in both cases a larger number of settlements with grid access. In these solutions off-grid is dominated by mini-grid solutions rather than stand-alone solar or wind which are used in a few settlements in either case. This is consistent with the suggestion of IEA (2011) that off-grid electricity access investments in the coming decades are likely to be dominated by mini-grids rather than standalone off-grid technologies. Figure 3 provides a picture of the spatial differences across the PA, DA and HLM solutions. In Figure 3 the white (hollow) region signifies the assumed currently electrified space in Ghana. In all three solutions grid extension is suggested for the settlements in the highly clustered and high demand South-West region, with little or no grid extension suggested in the North and NorthEast, reflecting the fact that settlements in that region are relatively sparse, poorer and have lower electricity demand. 


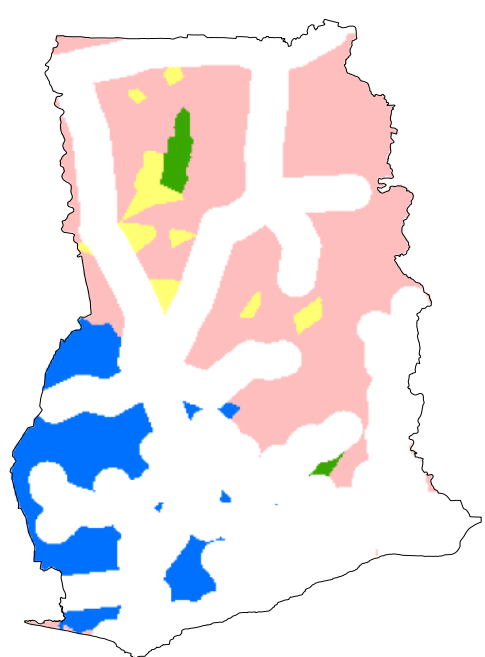

a: HLM

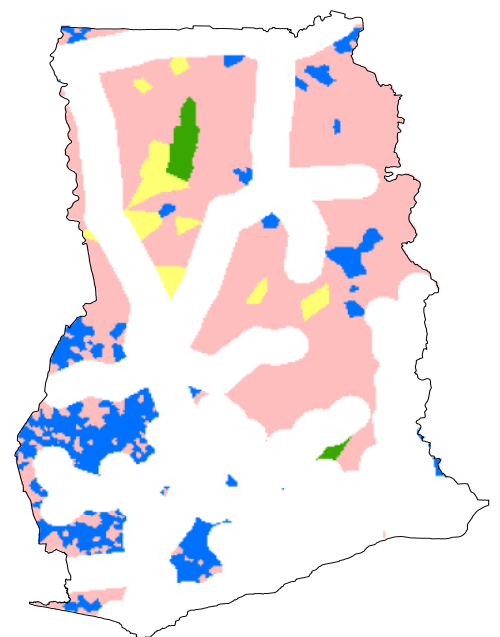

b: PA

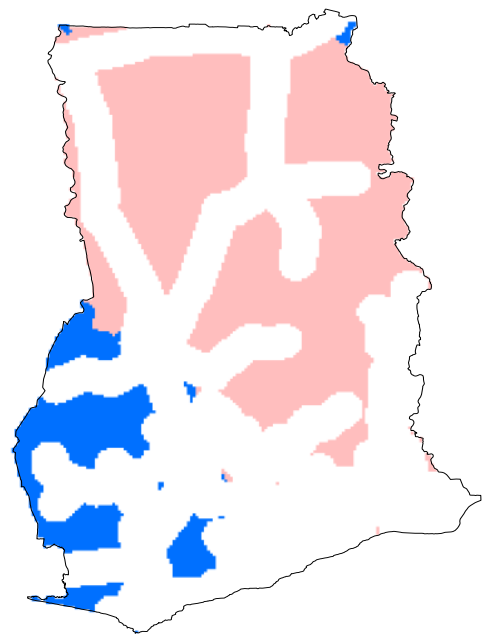

c: DA

\section{Legend}

Grid

Minigrid

Solar

Wind

Figure 3: Spatial distribution of technologies: HLM versus other methods

Figure 4 illustrates the detailed spatial pattern for the three solutions for the South-West region of Ghana. This shows that in contrast to the other solutions the PA method has a significantly finer technology frontier between grid and off-grid electrification, with many relatively geographically close settlements served differently. In contrast, the DA and proposed HLM solutions are much more geographically uniform. These results reflect the underlying heuristic used in each method. 


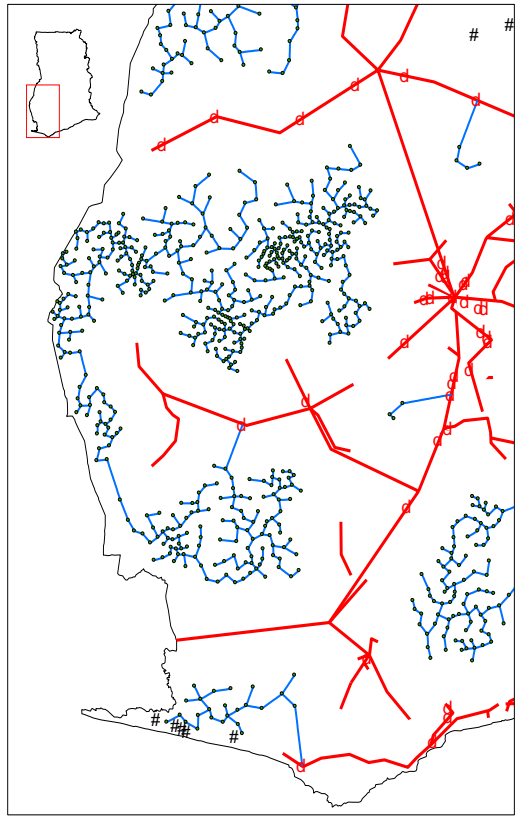

a:HLM

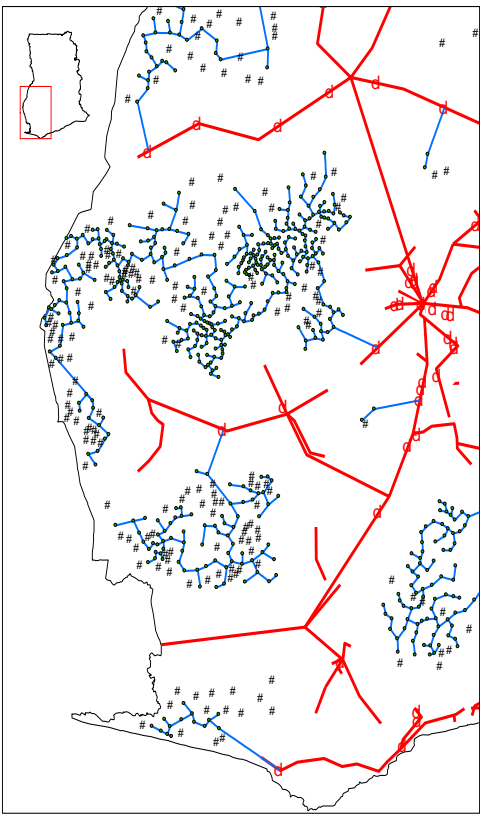

b: PA

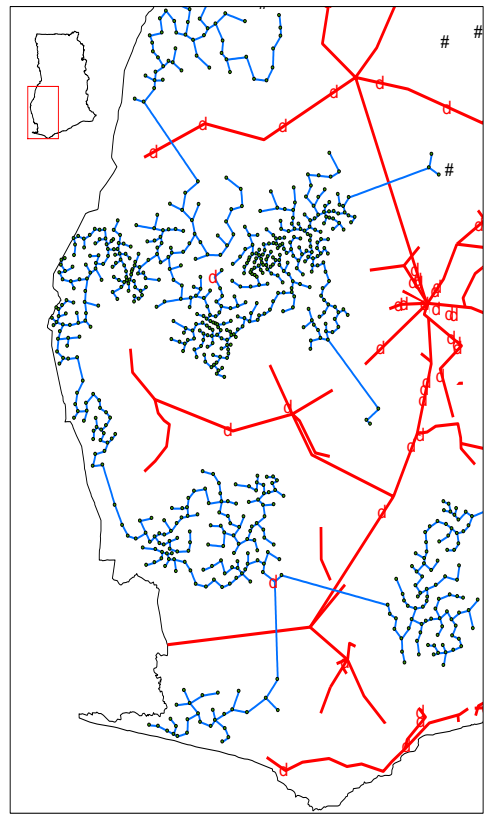

c: DA

\section{Legend}

\# Off-grid settlements

d Generation/BSP location

New MV distribution

Existing transmission line

Figure 4: Grid versus off-grid technology frontier: HLM versus other methods

\subsection{Prioritising Population}

In Figure 5, we illustrate the solution where maximizing population is now the first priority in the HLM algorithm. Relative to Figure 2, we can see that changing the first objective effectively eliminates any trade-off between grid connection and off-grid in terms of cost. As grid connection increases overall costs do initially fall slightly with an increase after 62 settlements. However, the variation in total costs of ensuring universal access is relatively small with only a $10 \%$ difference in the minimum cost ( $\$ 4.992$ billion) and the maximum cost $(\$ 5.528$ billion $)$. 


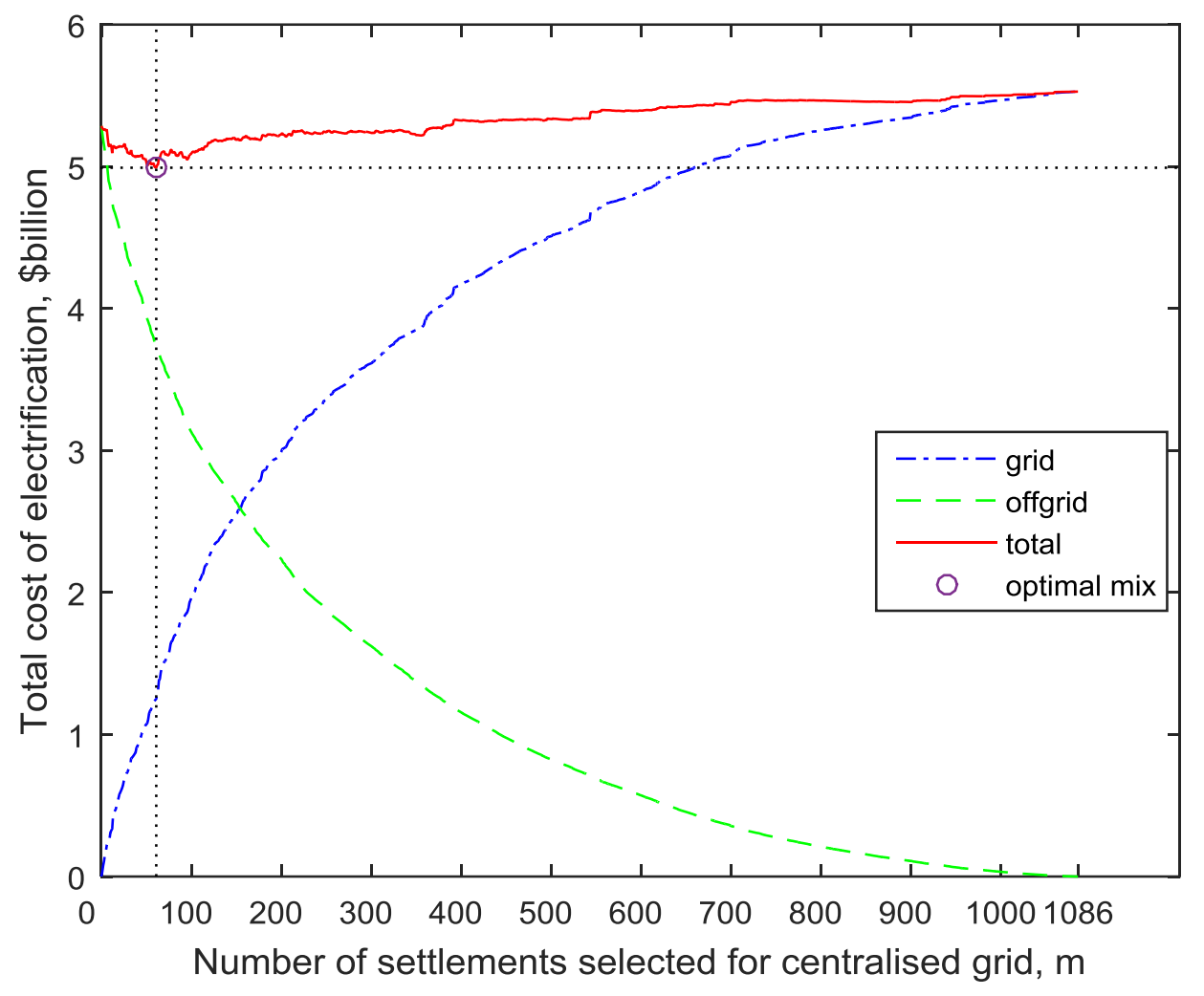

Figure 5: HLM solution prioritising population: Total cost and cost structure by number of grid connected settlements.

As shown in Table 2, when cost efficiency is the priority off-grid technologies appear to offer an alternative to grid extension, implying that policy makers should consider differentially investing in grid and off-grid to help achieve cost effective universal electrification. However, the limited cost advantage offered by off-grid technologies when population is prioritized mean its role for policy makers is less clear cut in this case. Here the solutions are consistent with governments first prioritising investment in grid extension and then using offgrid as secondary (and intermediate step) solution, which do appear to align more with practice (Bhattacharyya, 2013).

As a result the important trade-offs for policy makers also change. In particular, as government budgets for grid investment are limited, policy makers need to consider the effectiveness of grid investment if they prioritise population rather than demand. Figure 6 
illustrates one important trade-off in this case, i.e. what is the population covered by grid for a given level of grid investment when demand and population are prioritised. For any given grid investment the vertical difference between the curves capture the extent to which prioritizing population or demand will affect the population covered. For any given population covered, the horizontal distance between the curves measures how much more (or less) grid investment is required to achieve this level of population coverage. The largest vertical distance between the two solutions occurs at the minimum HLM solution prioritizing demand found in Table 2. Consistent with this, Figure 6 indicates that a grid investment of $\$ 1.68$ billion prioritising demand would lead to a grid network covering 1.54 million people (i.e. $47.7 \%$ of the currently un-electrified population). However, at this level of grid investment significantly fewer people are grid connected when population is prioritised (around 1.2 million people). Similarly the horizontal distance in the figure shows the extra cost required to extend the grid to the same level of population when population is prioritized. Hence, to cover 1.54 million people with the grid when prioritizing population rather than demand would require an increase in grid investment of around \$740 million. 


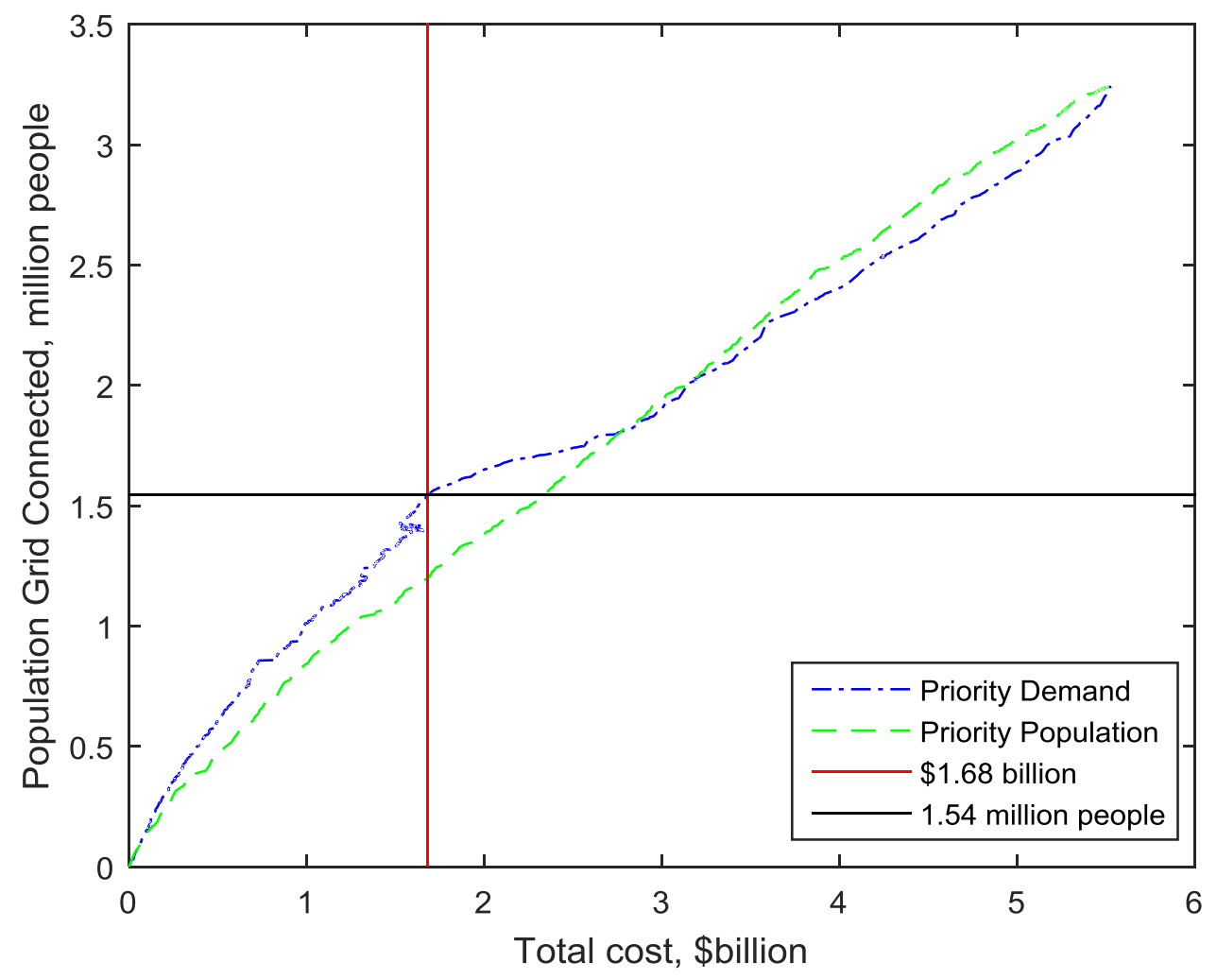

Figure 6: Effectiveness of grid investment: Prioritising demand (i.e. cost efficiency) versus population (i.e. considering politico-economics).

However, the trade-offs between the two approaches are less when grid investment is above or below $\$ 1.68$ billion. Indeed at higher levels (around $\$ 3$ billion) the two curves cross and the solution prioritizing population is more effective in achieving grid connection for more people at the same cost than the demand based solution.

Changing the priorities also significantly affects the implied spatial solution of the grid. To provide an indication of this, Figure 7a (repeating Figure 3a) illustrates the HLM solution prioritising demand at the minimum found in Table 2, i.e. with a grid investment of $\$ 1.68$ billion covering 1.54 million people. As a comparison Figure 7b illustrates the HLM solution prioritising population when 1) grid investment is $\$ 1.68$ billion while Figure $7 \mathrm{c}$ set the grid investment such that 1.54 million people are covered by the grid. The regional differences across the solutions are striking with the solutions prioritising population leading to extensive 
grid extension in the North and East of the country whereas the demand priority concentrates grid extension in the high demand areas of the South West.

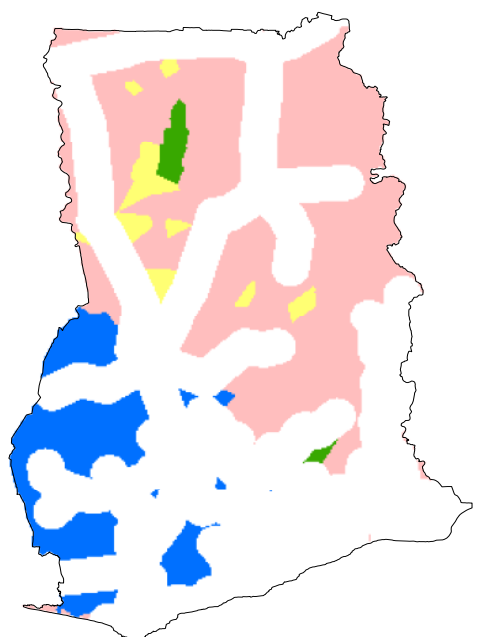

a: Demand priority: $\$ 1.6$ billion grid investment and 1.54 million grid connected

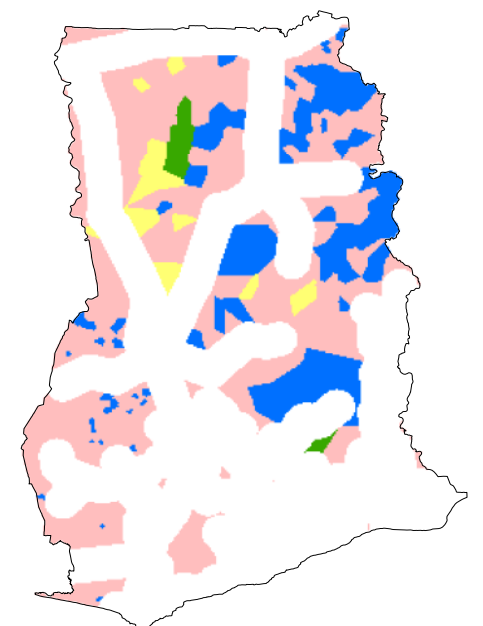

b: Population priority: $\$ 1.6$ billion grid investment

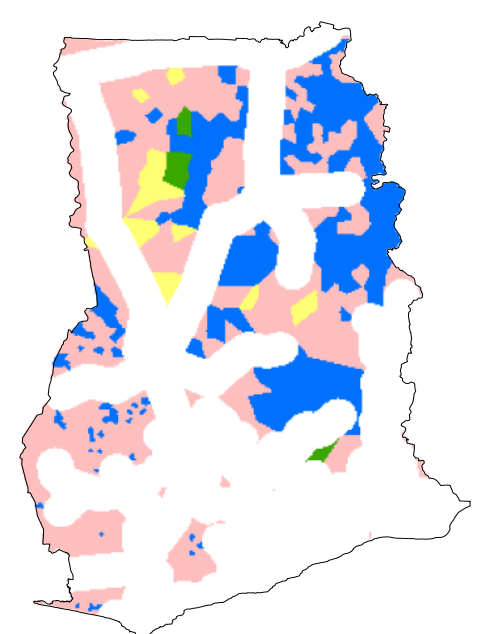

c: Population priority: 1.54 million grid connected

$$
\begin{aligned}
& \text { Legend } \\
& \text { Grid } \\
& \begin{array}{|l}
\hline \text { Minigrid } \\
\text { Solar } \\
\text { Wind }
\end{array}
\end{aligned}
$$

\section{Figure 7: Spatial distribution of technologies: Prioritizing demand and population.}

\section{Conclusions and Policy Implications}

Off-grid technologies are increasingly proposed as a way of ensuring universal access to electricity in many developing countries. However, many communities would prefer access to electricity via the grid rather than an off-grid technology. The previous methods developed to plan how best to extend electricity access at a national level and the appropriate balance between grid and off-grid have typically focussed on cost effectiveness only. Using data on un-electrified communities in Ghana as a case study, we develop an algorithm based on hierarchical lexicographic programming and consider specifications where the priorities are adjusted to give weight to 1) cost efficiency by prioritising demand and 2) political economy 
considerations so that communities with large populations (and therefore votes) are given priority in terms of grid electrification.

Overall, the results emphasise the need to recognise political economy considerations in the national planning of universal electrification. For example the results suggest considerable regional differences across the cost efficiency and political economy type solutions in terms of where grid extensions ought to be placed. The solutions prioritising demand (which are more cost efficient) concentrate grid extension in the relatively more economically developed areas of the South West, while solutions prioritising population lead to greater grid extension effort in the North and East of the country. As regional political interests are very likely to be an important input into national grid electrification policy, solutions which only focus on cost efficiency at the national level are likely to be undermined by the political process.

Similarly, the results indicate that other methods focussing on cost efficiency need to consider the political feasibility of the plans which result. For example, the results show that when the Parshall et al. (2009) approach is used on the Ghanaian data, the solution implied that many relatively geographically close un-electrified settlements ought to be electrified differently, i.e. with grid or off-grid. From the perspective of the communities involved the rationale for why they do (or do not) get grid access may seem rather arbitrary. Therefore local political pressure for grid extension to off-grid communities may undermine the feasibility of such solutions, consistent with the evidence provided by Bawakyillenuo (2007, 2012) that political promises and apparent likelihood of grid connection has impeded the growth of off-grid technologies in Ghana.

When the objective is to prioritise demand the results of the hierarchical lexicographic programming method indicate trade-offs between off-grid and grid in broadly similar ways to 
those found using the standard methods by Parshall et al. 2009 and Deichmann et al. 2011. However when population is prioritised reflecting the political economy of electricity distribution, the trade-off between off-grid electrification and grid extension is much less apparent, with the total electrification cost relatively insensitive to the balance between the technologies. Rather here the solutions obtained are consistent with governments first prioritising investment in grid extension and then using off-grid as secondary (and intermediate step) solution for universal access.

One key implication of this is that incorporating political economy goals changes which policy trade-offs are most important. In particular, rather than focussing on off-grid technologies as a way of minimizing total costs, the key issue becomes the effectiveness of grid investment in providing access if policy makers plan grid extension on the basis of political economy criteria other than cost efficiency (World Bank, 2006, 2008). The results illustrate the potential magnitude of these trade-offs by showing that when population is prioritised over demand the population covered by grid for a given level of grid investment can be significantly less.

The results for the Ghana data presented here are indicative and more up to date and detailed data e.g. from energy utilities, would be needed if the results were to be used for an actual planning exercise. However, the results do suggest that generally models for planning universal electrification at a national level ought to routinely account for the impact of political economy factors. The political economy of electrification clearly often affects policy makers' decisions in practice and our case study results show that this can have significant effects. Focussing on cost efficiency and a trade-off of grid versus off grid which may not be policy relevant means current planning models may be failing to provide policy makers with 
information on the real trade-offs which they face. This also underlines the need to more closely adapt planning models to the reality of the planning problem faced by policy makers. If off grid is (for most) going to be seen as an intermediate step before grid connection, and if tools for national planning are to be effective in providing support to policy makers then models need to be developed to better able deal with the dynamics of planning. That is, when should communities be connected via off-grid, when should they wait for grid connection, if they are connected via off-grid when should grid be extended to them?

\section{Acknowledgement}

The first author would like to thank the University of Aberdeen and the Henderson Economics Research Fund for funding his PhD studies in the period 2011-2014 which formed the basis for the research presented in this paper. 


\section{References}

Abdul-Salam, Y., 2015. Access to electricity in sub-Saharan Africa: Modelling the importance and adoption of off-grid renewables. (Doctoral dissertation, University of Aberdeen).

African Development Bank (ADB) Group, 2011. ArcGIS shapefile for Ghana power plants data. Available at http://www.infrastructureafrica.org/documents/tools/list/arcgis-shapefiles?page $=4$ (accessed December 2011).

Afripop, 2012. Population GIS data for Ghana. Available at http://www.afripop.org/ (accessed January, 2012).

Amador, J., Domínguez, J., 2005. Application of geographical information systems to rural electrification with renewable energy sources. Renew Energ, 30(12), 1897-1912.

Banerjee, A., Somanathan, R., 2007. The political economy of public goods: Some evidence from India. J Dev Econ, 82(2), 287-314.

Bawakyillenuo, S. 2007. Rural electrification in Ghana: Issues of photovoltaic energy technology utilization (Doctoral dissertation, University of Hull).

Bawakyillenuo, S. 2009. Policy and institutional failures: Photovoltaic solar household system (PV/SHS) dissemination in Ghana. Energy and Environment, 20(6), 927-947.

Bawakyillenuo, S. 2012. Deconstructing the dichotomies of solar photovoltaic (PV) dissemination trajectories in Ghana, Kenya and Zimbabwe from the 1960s to 2007. Energy Policy, 49, 410-421.

Bergey, P.K., Ragsdale, C.T. Hoskote, M., 2003. A simulated annealing genetic algorithm for Electrical Power Districting Problem. Ann Oper Res 121. 33-55.

Bhattacharyya, S. C., 2006. Energy access problem of the poor in India: Is rural electrification a remedy? Energy Policy, 34(18), 3387-3397.

Bhattacharyya, S. C., 2013. To regulate or not to regulate off-grid electricity access in developing countries. Energy Policy, 63, 494-503.

Brown, D. S., Mobarak, A. M., 2009. The transforming power of democracy: regime type and the distribution of electricity. Am Polit Sci Rev, 103(02), 193-213.

Buys, P., Deichmann, U., Meisner, C. M., That, T. T., Wheeler, D., 2007. Country stakes in climate change negotiations: two dimensions of vulnerability. World Bank Policy Research Working Paper, (4300).

Clark, P. J., Evans, F. C., 1954. Distance to nearest neighbor as a measure of spatial relationships in populations. Ecology, 445-453. 
Deichmann, U., Meisner, C., Murray, S., Wheeler, D., 2011. The economics of renewable energy expansion in rural sub-Saharan Africa. Energy Policy, 39(1), 215-227.

Ghana Grid Company (GRIDCO), 2011. Available at http://www.gridcogh.com/ (accessed December 2011)

Ghana Statistical Service, 2010. 2010 Population and housing census. Summary report of final results. Available at http://www.statsghana.gov.gh/docfiles/2010phc/Census2010_Summary_report_of_final_resu lts.pdf (Accessed August 2015).

Ghana Statistical Service, 2012. Available at http://www.statsghana.gov.gh/ (accessed January 2012)

Goldemberg, J. , 2000. World energy assessment: Energy and the challenge of sustainability. United Nations Publications.

International Energy Agency (IEA), 2011. World Energy Outlook (WEO). Available at https://www.iea.org/publications/freepublications/publication/world-energy-outlook-

2011.html (accessed February 2015)

International Energy Agency (IEA), 2014. World Energy Outlook (WEO). Available at http://www.worldenergyoutlook.org/publications/weo-2014 (accessed August 2015)

Kalvelagen, E., 2002. Solving multi-objective models with GAMS. GAMS Development Corporation.

Kemausuor, F., Adkins, E., Adu-Poku, I., Brew-Hammond, A., Modi, V., 2014. Electrification planning using network planner tool: The case of Ghana. Energy Sustain Dev, 19, 92-101.

Kemausuor, F., Obeng, G. Y., Brew-Hammond, A., \& Duker, A., 2011. A review of trends, policies and plans for increasing energy access in Ghana. Renew Sust Energ Rev, 15(9), 5143-5154.

Kruskal, J. B., 1956. On the shortest spanning subtree of a graph and the traveling salesman problem. P Am Math Soc., 7(1), 48-50.

Lambert, T. W., Hittle, D. C., 2000. Optimization of autonomous village electrification systems by simulated annealing. Sol Energy, 68(1), 121-132.

Levin, T., Thomas, V. M., 2012. Least-cost network evaluation of centralized and decentralized contributions to global electrification. Energy Policy, 41, 286-302.

Min, B., 2011. Electrifying the Poor: Distributing Power in India. Ann Arbor 1001 (2011): 48109-1045. 
Nguyen, K. Q., 2007. Alternatives to grid extension for rural electrification: Decentralized renewable energy technologies in Vietnam. Energy Policy, 35(4), 2579-2589.

NREL, 2010. Cost and Performance Assumptions for Modelling Electricity Generation Technologies. Available at http://www.nrel.gov/docs/fy11osti/48595.pdf (accessed September 2015)

Painuly, J. P., Fenhann, J. V., 2002. Implementation of renewable energy technologiesopportunities and barriers. summary of country studies Ris $\varnothing$ National Laboratory. UNEP Collaborating Centre on Energy and Environment.

Palit, D., Chaurey, A., 2011. Off-grid rural electrification experiences from south asia: Status and best practices. Energy Sustain Dev, 15(3), 266-276.

Parshall, L., Pillai, D., Mohan, S., Sanoh, A., Modi, V., 2009. National electricity planning in settings with low pre-existing grid coverage: Development of a spatial model and case study of kenya. Energy Policy, 37(6), 2395-2410.

Pokharel, S., 2004. Energy economics of cooking in households in Nepal. Energy, 29(4), 547-559.

Scott, A., Seth, P., 2013. The political economy of electricity distribution in developing countries. Journal of Policy and Governance.

Sanoh, A., Parshall, L., Sarr, O. F., Kum, S., Modi, V., 2012. Local and national electricity planning in Senegal: Scenarios and policies. Energy Sustain Dev, 16(1), 13-25.

Solar and Wind Resource Assessment (SWERA), 2011. Available at http://en.openei.org/wiki/SWERA/Data (accessed December, 2011)

World Bank. 2006. Peru-Rural Electrification Project. Project appraisal document report No. 32686-PE, World Bank, Washington, DC

World Bank. 2008. The welfare impact of rural electrification: A reassessment of the costs and benefits. Available at http://siteresources.worldbank.org/EXTRURELECT/Resources/full doc.pdf (February 2014)

Zvoleff, A., Kocaman, A. S., Huh, W. T., \& Modi, V., 2009. The impact of geography on energy infrastructure costs. Energy Policy, 37(10), 4066-4078 


\section{Appendix A}

Table A1: Component costs: Cost assumptions for components of competing technologies. Sources: Parshall et al. (2009), Renewables Report (2013)

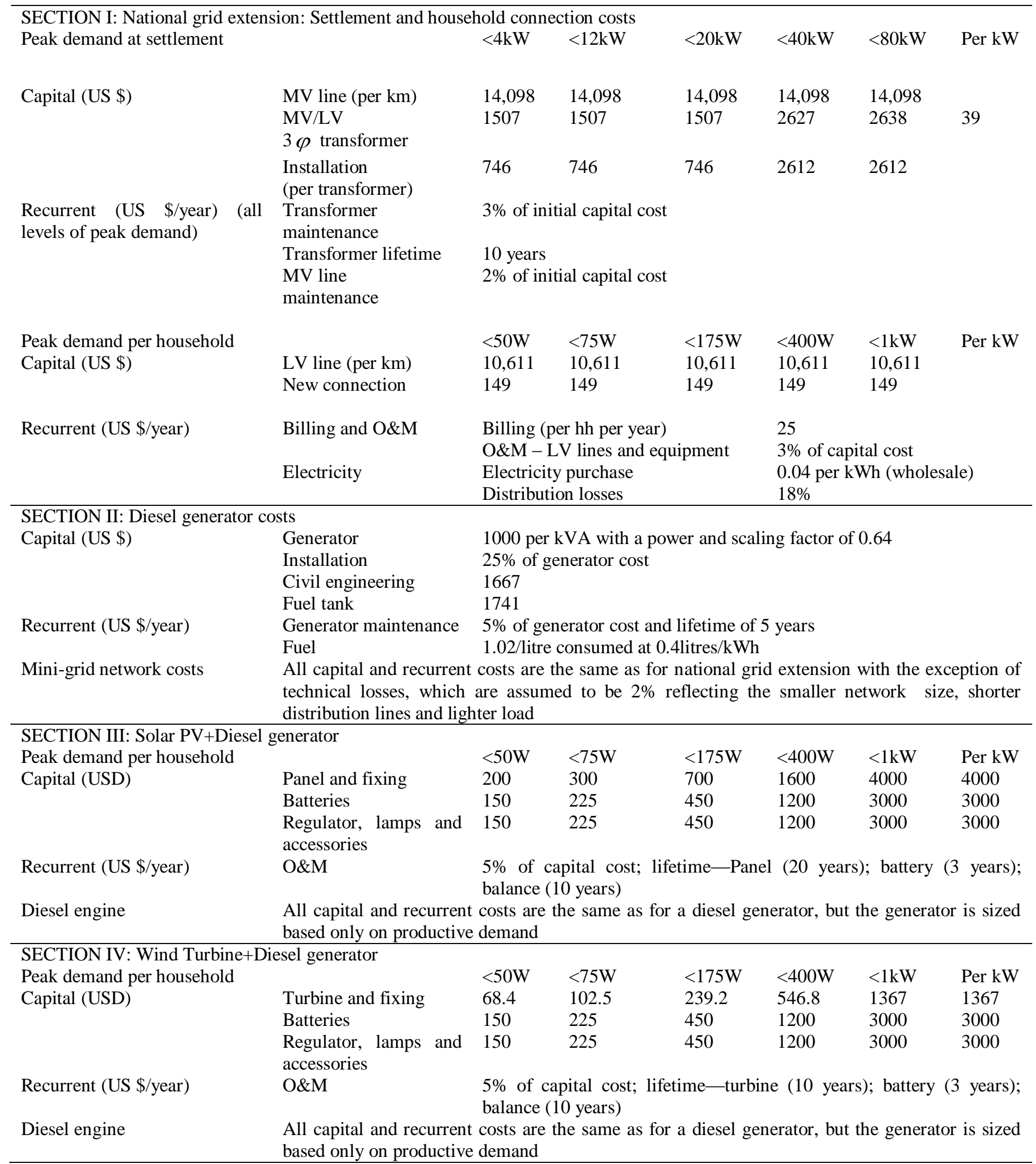


